\title{
Multiple cutaneous nerve abscesses on a healed tuberculoid patch
}

\author{
U SAXENA, S RAVI, V RAMESH, R S MISRA \& \\ ASHOK MUKHERJEE* \\ Department of Dermatology and Institute of Pathology (ICMR)*, \\ Safdarjang Hospital, New Delhi 110029, India
}

Accepted for publication 19 December 1989

Summary A case of healed tuberculoid leprosy (TT) with multiple superficial nerve abscesses involving the whole cutaneous network on the patch is reported. To the best of our knowledge multiple cutaneous nerve abscesses involving the entire subcutaneous plexus on a TT patch is a very uncommon observation.

\section{Introduction}

Nerve abscesses in leprosy are usually seen in paucibacillary leprosy particularly during reaction, but have rarely been reported in multibacillary leprosy. ${ }^{1-4} \mathrm{~A}$ case of TT with multiple nerve abscesses involving the entire superficial cutaneous network over the lesion is reported.

\section{CASE REPORT}

A 58-year-old Indian male dairy worker and a resident of Haryana, India (a low endemic state) presented 6 years previously with an erythematous lesion on the posterolateral aspect of the left forearm of $2 \frac{1}{2}$ months duration. The lesion gradually increased in size and within the next $1 \frac{1}{2}$ months the patient noticed complete loss of sensation over the area. There was no history of similar lesions in the family or close contacts.

On examination of the skin there was an oval well-defined lesion, $10 \times 5 \mathrm{~cm}$ in size, on the posterolateral aspect of left forearm. It was erythematous, rough, dry and with raised infiltrated borders. There was complete loss of sensation over the patch. Nerves leading to the patch were palpable and nontender. The ulnar nerve on the affected side was uniformly thickened and nontender. There was no other positive finding on cutaneous and systemic examination. A clinical diagnosis of TT leprosy was confirmed by histopathological examination and a strongly positive lepromin test. No acid-fast bacilli were seen in the section.

The patient received dapsone monotherapy $100 \mathrm{mg}$ daily for one year. There was gradual improvement of the lesion. It became flattened, hypopigmented, slightly atrophic 
with loss of activity. Nerves to the patch were still palpable and nontender. A follow-up biopsy was taken after one year of treatment which showed chronic inflammatory infiltration and a few remnant granulomas with no evidence of active disease. In view of his clinical and histopathological inactivity and strong positive lepromin, dapsone was stopped and the patient was put under surveillance. Two months later the patient noticed some papulonodular lesions on the patch. These nodules persisted without any evidence of clinical activity. At the end of 4 years of discharge from treatment the cutaneous examination revealed a slightly hypopigmented atrophic patch studded with as many as 17 papulonodular swellings, which were superficial, firm, freely mobile and ranged from 0.5 to $1 \mathrm{~cm}$ in size (Figure 1). An X-ray of the forearm did not show any evidence of calcification in the nodules. Histopathological examination of a nodule revealed a central area of caseation lined by a zone of epithelioid and giant cells and a layer of compressed fibrous tissue. No residual nerve fibres were seen. These features were characteristic of a caseating nerve abscess with no histopathological evidence of calcification (Figure 2). The cutaneous biopsy taken simultaneously showed features of subsided disease. The patient was later put on paucibacillary MDT for 6 months, with no change in the nodular thickenings at the completion of the regimen.

\section{Discussion}

Thickened nerves are characteristic of tuberculoid leprosy. There may occasionally be a nerve abscess in association with active tuberculoid lesion, but the abscesses are a manifestation of the reactional state of tuberculoid leprosy, of ten in association with a thickened and tender nerve. They are of the nature of cold abscesses and may appear as fusiform fluctuant swellings along the course of the nerve, or as a globular swelling by the side of the nerve. ${ }^{5}$ In most cases these abscesses persist after the reaction has subsided and eventually they may undergo calcification. The most common sites are the ulnar and

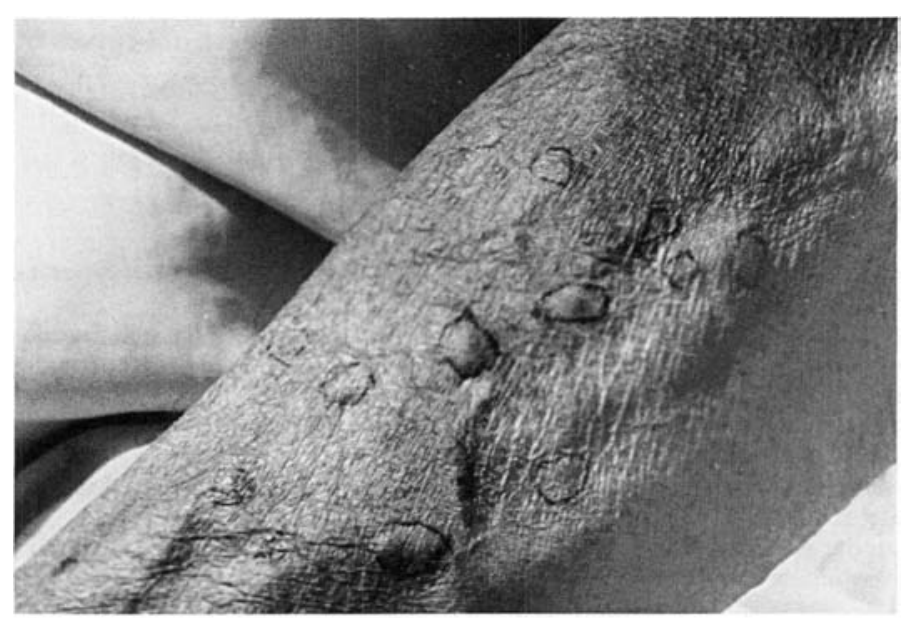

Figure 1. Forearm showing nodular swellings and nerve to the patch. 


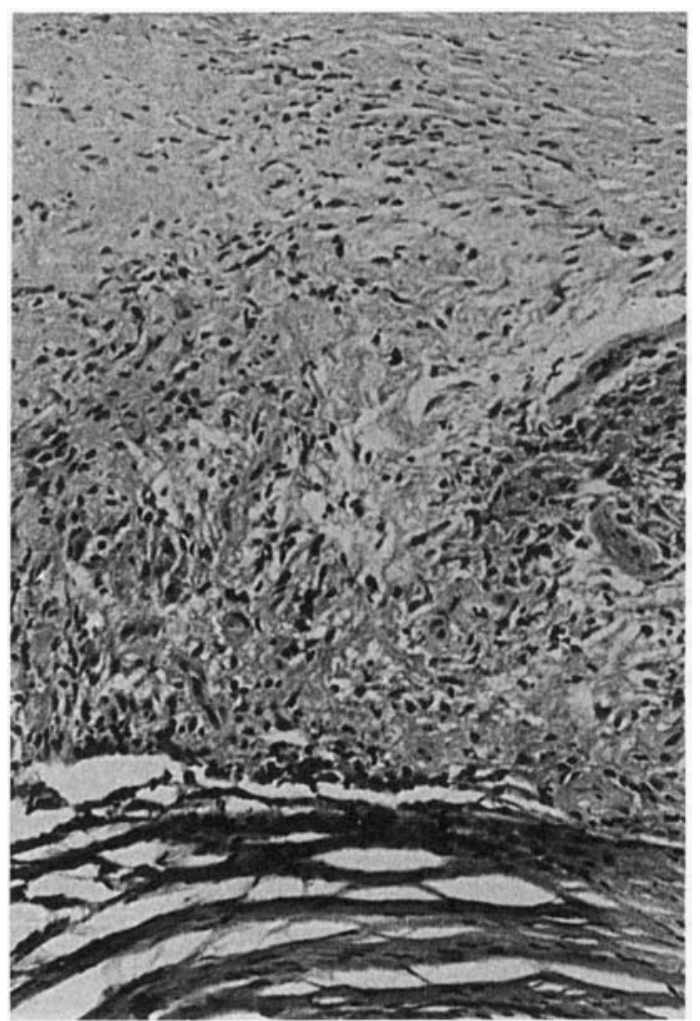

Figure 2. Section of a subcutaneous nodule showing caseation, epithelioid and giant cells in the centre, and peripheral fibrosis.

lateral popliteal nerve trunks, ${ }^{6}$ although median and posterior tibial nerves are also involved. The present case is curious because of the involvement of the superficial cutaneous nerve plexus which was studded with multiple nerve abscesses over a healed TT patch.

\section{References}

1 Sato S. Nerve abscess in lepromatous leprosy-Report of a case with a review of reports of nerve abscess in Japan. Int J Lepr, 1956; 24: 408-18.

2 Job CK, Bhaktaviziam C. Nerve abscess in lepromatous leprosy report of a patient. Lepr Rev, 1967; 38: 243-7.

${ }^{3}$ Enna CD, Brand PW. Peripheral nerve abscess in leprosy-Report of three cases encountered in dimorphous and lepromatous leprosy. Lepr Rev, 1970; 41: 175-80.

${ }^{4}$ Chaudhary RSB, Srinivasan H. Nerve abscess in lepromatous leprosy-A case report and a discussion of pathogenesis. Lepr India, 1977; 49: 330-8.

5 Ramu G, Dharmendra. Acute excerbations in leprosy. In Leprosy, Volume 1. Bombay: Kothari Medical Publishing House, p. 111.

${ }^{6}$ Siddappa K, Inamdar AC, Basavraj GC, Chandra Shekhar NR. Calcification of ulnar nerve in a patient with tuberculoid leprosy a case report. Ind J Lepr, 1989; 11: 107-10. 